\title{
Observations on Filarial Infection in Amassoma Community in the Niger Delta, Nigeria
}

\author{
AGI, P.I.; EBENEZER, A. \\ Department of Animal and Environmental Biology, \\ University of Port Harcourt \\ P.M. B. 5323. Port Harcourt, Rivers State, Nigeria.
}

\begin{abstract}
Filarial infections were studied in Amassoma community between March 2006 and April 2007. Seven hundred and eighty blood samples were obtained and examined using standard parasitological techniques. Of this number, 227 (25.5\%) samples were infected with filarial spp as follows: Mansonella perstans 121 (43.8\%), Wuchereria bancrofit 80 (28.8\%), Loa loa 75 (27.1\%) and Onchoceria volvulus 1 (0.3\%). Peak infection (44.3\%) occurred in the 30-39 years age bracket. The lowest infection rate was observed in the candidates above 70 years old. Microfilarial density (mfd) was highest in this age bracket. The lowest mfd occurred in 1-9 years old. Infection was higher $(38.9 \%)$ in the males than in the females $(33.9 \%)$. Higher infection in the males was attributed to fishing, which was predominantly a male occupation. Three of the five mosquito spp collected from the community hardboured microfilariae: Anopheles gambiae (9.5\%), A-funestus (6.6\%), Culex quinquefestus (4.1\%), Anopheles nili $(-\%)$, Aedes aegypti $(0 \%)$. The presence of the microfilariae confirms that filarial infections in the study area are endemic. Entomological survey was done in the night and insects that were active in day-time were not trapped. @ JASEM
\end{abstract}

The increasing trend of filarial infection in Nigeria, particularly in the Niger Delta is disturbing, despite improvements in the health care delivery system (Ogunba, 19771 Udonsi, 1980). Filariasis has been endemic in the Niger Delta since time immemorial, but studies on its pattern of infection began in the late 1980's (Udonsi and Odey, 1985; Arene and Atu, 1986; Udonsi, 1998). Recent studies on filariasis in the area have shown focal distribution of the disease (Braide et al. 2003; Amadi and Udonsi, 2004).

Information on the status of filarial infection in the Niger Delta is not completely known and the entire distribution pattern of filariasis in the area is far from being comprehensive. Much of the work on filariasis in the Niger Delta however, was carried out in the eastern axis of the area, probably because of the difficult ecological terrain of the central and western sections (Arene and Atu, 1986; Udonsi, 1986).

The present exercise was conducted in Amassoma community because of its importance as a University Community (Niger Delta University- Bayelsa State, Nigeria) and also as a prominent ancient community of the Ijaw tribe. The studies were conducted between March 2006 and April 2007, to provide base-line data on filarial infection in central area of Niger Delta.

\section{MATERIALS AND METHODS}

\section{The Study area}

Amassoma community is 20 kilometes from Yenagoa, the state capital of Bayelsa State, Nigeria. The community is located between latitude $4^{\circ} 57^{\prime}-$ $4^{\circ} 58^{\prime} \mathrm{N}$ and longitude $6^{\circ} 9^{\prime}-6^{\circ} 10^{\prime} \mathrm{E}$. The area has humid semi-hot equatorial climate of the Af type of Koppen's system, (Alagoa, 1999, Agi 1995). The topography is characterized by a maze of affluent, creeks and swamps crossing the low-lying plains of the Niger Delta in varying dimensions. Annual rainfall is $3000 \mathrm{~mm}^{3}$ and rainy season lasts ten months. Much of the area is permanently water-logged. The vegetation is fresh-water swampy forest. Settlement pattern is a clustered type and people are confined to families and compounds (loc. Cit.). Some houses bear reminiscent of traditional architecture with mud walls and thatched roofs (Agi 1995). Subsistent farming and fishing are the two occupations engaged by the community. These occupations run along gender lines. Faming is done by the females while fishing is predominantly a male occupation and done more intensively at night. There are few health centres and relatively fewer qualified personnel to mange.

\section{Collection of blood samples}

Informed consent was obtained from participants through their community heads who were communicated by the Director of Primary Health Care and State Epidemiologist, Ministry of Health, Yenagoa, Bayelsa State, for this exercise. On the agreed date, the community heads and community Health Assistant mobilized a large crowd of volunteers at the Town Hall for sample collection. Both sexes and all the age groups between one year and seventy years of age were represented. The filed team was made up of a staff Nurse from one of the Community Health Care centres, two technicians and the Community Health Assistant.

Bio-data of each participant was obtained through a questionnaire which elicited responses for name, sex, age, occupation as well as their perception of filarial infection. The community health assistant was very useful in this regard through the use of both 'pigin' English and local dialect to obtain responses.

Night blood sample (NBS) could not be collected in 
the community because the cultural norms prohibited such practices. Rather, the day provocative test (DPT) for Wuchereria filariasis was adopted using diethyl carbamazine citrate (DEC) marketed as Banocide. DEC was obtained from Niger Bay Pharmacy store, Port Harcourt. Hundred milligrams $(100 \mathrm{mg})$ of DEC was administered to participants above 15 years of age and $75 \mathrm{mg}$ was given to those below 15 years (Udonsi 1986). Pregnant women did not receive the drug for obvious medical reasons.

Day provocative samples (DPS) was collected after 50-55 minutes of DEC administration. Two milliliters $(2 \mathrm{ml})$ of blood was drawn from each participant intravenously into a heparinized tube containing $0.5 \mathrm{ml}$ acetic acid. All the samples were taken to Tobis diagnostic laboratory, Yenagoa, for examination.

\section{Examination of blood samples}

A modified Knott's concentration technique described by Udonsi (1986) was used to detect the presence of microfilariae in the blood. Aliquots $(\mathrm{lml})$ of blood were mixed with $10 \mathrm{ml}$ of $2 \%$ formalin in a $5 \mathrm{ml}$ centrifuge tube and centrifuged at $1500 \mathrm{rpm}$ for 15 minutes. The blood in the tube formed three layers as follows: serum, white blood cell and red blood cell layers. The supernant was decanted using Pasteur's pipette. Aliquots of the white cell sediment was pipetted onto a grease-free slide and covered with coverhslip and viewed under the microscope.

Species of microfilariae in positive blood samples were identified by smearing the sediments on a slide and allowing it overnight, to dry. The slide was stained with $8 \%$ phosphate buffer $(\mathrm{pH} 7.2)$ Giemsa stain. This was rinsed in buffered water and finally in distilled water and kept to dry. Microfilariae were identified and counted under the microscope using the nature of the sheath and the position of the nuclei (Udonsi, 1986).

\section{Collection and identification of insect vectors:}

Three volunteers were positioned outside the houses in each village to serve both as human baits and collectors of the mosquitoes. Each volunteer was given a collecting sucker by means of which adult female mosquitoes were sucked into the tube when feeding on the volunteers. Time of collection was between 10.00 p.m. and 4.00 a.m. each day. The mosquitoes collected were transferred to a glass container with cotton wool soaked chloroform and sent to the laboratory for identification and examination of infection. The identification of mosquitoes was done using the key prepared by Gordon and Lavopierre (Gordon \& Lavoipiere, 1978).

\section{Examination of mosquitoes for infection}

The mosquitoes were placed each in one drop of physiological saline, after removing the legs and the wings. The head, thorax and abdomen were separated using dissecting needles. Each section of the body was teased and examined under a dissecting microscope for the presence of microfilariae (Gorden and Lavoipiere, 1978).

\section{RESULT}

\section{Distribution of infection by age and sex} Out of the 780 blood samples examined, 227 $(35.5 \%)$ were infected with filarial worms (Table 1). Filarial species encountered were Mansonella perstan 121(43.8\%), Wuchereria bancrofti 80(28.9\%), Loa loa 75(27.1\%) and Onchocerca volvulus $1(0.3 \%)$.

TABLE 1: Age distribution of filarial infection in relation to species of filarial worms in Amassoma community

\begin{tabular}{lllllll}
\hline AGE & NO & \multicolumn{6}{l}{ SPECIES OF FILARIAL WORMS } \\
\hline Group & Exam. & Infected & $\mathrm{Mp}$ & $\mathrm{Wb}$ & $\mathrm{Li}$ & $\mathrm{Ov}$ \\
$1-9$ & 98 & $24(24.5)$ & $12(50.0)$ & $5(20.8)$ & $7(20.2)$ & - \\
10.19 & 126 & $43(34.1)$ & $1.8(41.9)$ & $11(25.6)$ & $14(32.5)$ & - \\
$20-29$ & 134 & $56(41.8)$ & $24(42.8)$ & $17(30.4)$ & $15(27.8)$ & - \\
$30-39$ & 122 & $54(44.3)$ & $26(48.1)$ & $15(27.8)$ & $13(24.0)$ & - \\
$40-49$ & 94 & $36(38.3)$ & $16(44.5)$ & $8(22.3)$ & $11(30.5$ & $1(1.06)$ \\
$50-59$ & 76 & $27(35.5)$ & $9(33.3)$ & $12(44.4)$ & $6(22.2)$ & - \\
$60-69$ & 74 & $24(32.4)$ & $9(37.5)$ & $7(29.2)$ & $8(33.3)$ & - \\
70 & 56 & $13(23.2)$ & $7(53.8)$ & $5(38.5)$ & $1(7.1)$ & - \\
\hline Total & 780 & $277(35.5 \%)$ & $121(43.8 \%)$ & $80(28.9 \%)$ & $75(27.1 \%)$ & $(0.3 \%)$ \\
\hline
\end{tabular}

Mp: Mansonella perstans

Wb: Wuchereria bancofiti

Li: Loa loa

Ov: Onchocera vovulus
Peak infection (44.3\%) occurred within the age bracket of 30-39 years. The lowest infection $(23.2 \%)$ occurred in the 70 years age group, followed by that of the 1-9 years old (24.5\%). There was no significant difference between the percentage infections of the peak and the lowest 
infections. Infection rate increased with age from one year to 39 years and thereafter gradually declined.

Gender related infection (table 2) showed that 172 $(38.9 \%)$ males and $105(33.9 \%)$ females were infected. The disparity in gender rate of infection was not statistically significant at $5 \%$ level of confidence. Peak infection for male $(49.2 \%)$ and that of female $(38.6 \%)$ occurred at $30-39$ years age brackets for both sexes.

\section{DISTRIBUTION OF MICROFILARIAL DENSITY}

Table 2-3 shows range of microfilarial density ( $\mathrm{mfd}$ ) in $2 \mathrm{ml}$ of blood of infected individuals. The highest mfd for candidates below 19 years of age was between $11-30 \mathrm{mf} / 2 \mathrm{ml}$ of blood. While $38.8 \%$ of candidate above 70 years of age had the highest mfd of $51-100 \mathrm{ml} / 2 \mathrm{mf}$ of blood. In other words, mfd per unit volume of blood was highest in the oldest candidates and lowest in the youngest age groups.

TABLE 2: Age and sex distribution of filarial infection in AMassoma community

\begin{tabular}{lllll}
\hline Age group & \multicolumn{2}{c}{ Males } & \multicolumn{2}{c}{ Females } \\
\cline { 2 - 5 } (in year) & No. exam. & No (\%) infected & No. exam & No. (\%) inf. \\
$1-9$ & 52 & $13(25.0)$ & 46 & $11(23.9)$ \\
$10-19$ & 67 & $26(38.9)$ & 59 & $17(28.8)$ \\
$20-29$ & 76 & $35(46.1)$ & 58 & $21(36.2)$ \\
$30-39$ & 65 & $32(49.2)$ & 57 & $22(38.6)$ \\
$40-49$ & 53 & $22(41.5)$ & 41 & $14(34.1)$ \\
$50-59$ & 52 & $19(365)$ & 24 & $8(33.3)$ \\
$60-69$ & 47 & $17(36.2)$ & 27 & $7(25.9)$ \\
70 & 34 & $8(23.5)$ & 22 & $5(22.7)$ \\
\hline Total & 442 & $172(38.9 \%)$ & 310 & $105(33.9 \%)$ \\
\hline
\end{tabular}

TABLE 3: Age distribution of microfilarial density per $2 \mathrm{ml}$

\begin{tabular}{|c|c|c|c|c|c|c|}
\hline \multirow{2}{*}{$\begin{array}{l}\text { Age } \\
\text { Group }\end{array}$} & \multirow{2}{*}{$\begin{array}{l}\text { NO } \\
\text { Infected }\end{array}$} & \multicolumn{5}{|c|}{ No (\%) species of filarial worms } \\
\hline & & $1-5$ & $6-10$ & $11-30$ & $31-50$ & $51-100$ \\
\hline $1-9$ & 24 & $14(58.3)$ & $6(25.0)$ & $4(16.7)$ & $0(-)$ & $0(-)$ \\
\hline 10.19 & 43 & $26(60.2)$ & $9(20.9)$ & $8(18.6)$ & $0(-)$ & $0(-)$ \\
\hline $20-29$ & 56 & $30(53.6)$ & $12(21.4)$ & $10(17.9)$ & $4(7.1)$ & $0(-)$ \\
\hline $30-39$ & 54 & $24(44.4)$ & $11(20.4)$ & $7(13.0)$ & $8(14.8)$ & $4(7.4)$ \\
\hline $40-49$ & 36 & $14(38.8)$ & $8(22.2)$ & $4(11.1)$ & $5(13.8)$ & $5(13.8)$ \\
\hline $50-59$ & 27 & $4(14.8)$ & $5(18.5)$ & $3(11.1)$ & $7(25.9)$ & $8(29.6)$ \\
\hline $60-69$ & 24 & $4(16.7)$ & $2(8.3)$ & $6(25.0)$ & $7(29.2)$ & $5(20.8)$ \\
\hline 70 & 13 & $1(7.6)$ & $2(15.4)$ & $2(15.4)$ & $4(30.8)$ & $4(30.8)$ \\
\hline Total & & $117(42.2)$ & $55(19.9)$ & 44(15.9) & $35(12.6)$ & $26(9.4)$ \\
\hline
\end{tabular}

TABLE 4: Number and percentage infection of mosquito vectors in Amassoma community

\begin{tabular}{lll}
\hline Species of Mosquito collected & No. examined & No. (\%) infected with microfilariae \\
\hline Anopheles gambiae & 116 & $11(9.1)$ \\
A nili & 26 & - \\
A. funestus & 18 & $1(6.6)$ \\
Culex quniquefestus & 98 & $4(4.1)$ \\
Aedes aegypti & 34 & - \\
\hline Total & 292 & $16(5.5)$ \\
\hline
\end{tabular}

\section{Entomological Survey}

Five species of mosquitoes were caught from the study area (table 4). Three species were found infected with microfilariae in the following frequencies: Anopheles gambiae 11 (9.5\%), A funestus 1 (6.6\%) and Culex quinquefestus 4 (4.1\%). Overall infection of the mosquitoes was $16(5.5 \%)$.

\section{DISCUSSION}

Filariasis is endemic in the study community following the observation of microfilasriae in the blood samples of all the age groups. Furthermore the detection of infection in the mosquito vectors was a confirmation of filariasis endemicity in the community.

The occurrence of peak infection at 30-39 years age bracket is consistent with studies elsewhere (Ogunba 1977, Udonsi 1986) but different from that of Weil et al (1999) who observed higher infections only in the age groups below 30 years. This is probably because human beings develop partial immunity to filariasis over time.

Higher prevalence of infection in males was observed in all the age groups. This trend has been noted by other workers (Udonsi and Odey, 1985; Arene, Arere and Atu, 1986; Albuger que et al, 1995) and was attributed to greater exposure to mosquito bites through fishing which was more of a nocturnal activity. Higher prevalence of infection in 
females has been observed in coastal Ghana (Simonsen et al 1995). The contrast in these findings was thought to be related to fishing which has a high potential for exposing people to mosquito bits. In coastal areas of Ghana, females were more involved in coastal fishing and were therefore more infected with filariasis. In Amassoma it was the contrast.

Prevalence of infection was lowest in the age group of 70' years but mfd was highest in this age bracket. This could be a result of time dependent exposure to vector bits leading to an accumulation of $\mathrm{mf}$ inoculation over the years. This same reason could also account for the low mfd observed in the youngest candidates (1-9 years) in the study, who might have had less bites on the basis of their age.

The species of filarial worms encountered from this study have been observed in studies conducted elsewhere in Nigeria (Udonsi and Odey 1985; Udonsi 1986, Amadi and Udonsi 2004).

Only one case of Onchocerca volvulus infection was detected in the study. Report of structured interview with the infected individual showed that the victim was an immigrant from the onchocerciasis endemic Okigwe in lmo State, Nigeria, who was working as security guard in a local block Industry in Amassoma. Health statistics from the primary health care centre in the community did not confirm any observation of onchocerciasis in the area. It was therefore not endemic in the community.

The community's perception of filarial infection and filariasis was very low $(0.2 \%)$ expect for Loa loa which many of them admitted seeing across the eye of infected people. The degree of perception was merely a function of the level of education. The females were more disadvantaged as they were less educated.

Anopheles gambiae, A. funestus and Culex quniquefestus collected from the community were infected with microfilariae. The first two mosquito species have been incriminated with the transmission of bancrofti fllariasis in West Mrica (Gordon and Lavoipiere, 1978) and in Ghana particularly (Simonsen et al 1995). The low collection of mosquitoes during the survey was attributed to the burning of the leaves of Occinum gratissium (Yanana, in their local dialect), believed to keep mosquitoes, according to the community chief, out of human habitation. Chrysops which is the vector of Loa loa (Gordon and Lavoipiese, 1978) was not trapped during the entomological survey because its activity schedule, which is diurnal, was out of step with the timing of the insect collection during this study. Culicoides spp (vectors of Mansonella perstans) were also not collected during the survey. Their absence was attributed to their tiny body size as well as their time of feeding, which is early in the evening (Crupuscular) or in dull weather (loc. Cit).
As far as known, there are no records of entomological surveys in this area.

\section{REFERENCE}

Agi, PI (1995). Vesical Schistosomiasis at Odau Village in Ahoada Local Government Area, Rivers State, Nigeria West African Journal of Medicine 14 (1): 6-10.

Alagoa, EJ (1999). The land and people of Bayelsa State: Central Niger Delta: Onyoma Research Publications, Port Harcourt, Nigeria 167 pp.

Albugerque, MF; Marzochi, MC; Sabroza, PC; Silva, MR; Schindler, HC; Maciel, MC; Souza, W; (1995). Bancrofti filariasis in two Urban areas of Recife, Brazil: Pre-control observations on infections and disease. (Trans. R. Soc. Trop. Med. Hyg. 89 (4): 373-377.

Amadi CA ; and Udonis, Jk (2004). Filariasis in Ogoni land: Species diversity, Prevalence and Intensity of infection. Book of Abstract, Nig. J. Parasit: 91.

Arene, FOI and Atu, FN (1986). Mansonella perstan microfilaraemia among the Bior-community in the Niger Delta of Nigeria. Ann.Trop. Med. Parasit. 80 (60). 535-538.

Braide, EI; Ikpeme B; Edete, B; Atting, I (2003). Preliminary observation on the occurrence of Lymphatic filariasis in Cross Rivers, Nigeria. Nig. J. Parasit 24:9-16.

Dunyo, SK; Appawu, M; Nkrumah, FK; BaffiaWilmot, A; Pedersen, EM; Simonsen, PE (1996). Lymphatice filariasis in the Coast of Ghana. Trans R. Soc. TROP. Med. Hyg 90 (6): 634-688.

Gordon, RM and Lavoipierre, mmj; (1978). Entomology for students of Medicine, $5^{\text {th }}$ Ed. Blackwell Sc. Publ., London 330 pp.

Ogunba, E.O. (1977). Loa loa microfilaraemia in the Nigerian population . Trop geog. Med. 29:51-55

Simonsen, PE; Meyrowitseh, DW; Mekunde, W.H; Magunsen, P. (1995). Bancroftian filariasis: the pattern of microfilaraemia and clinical manifestations in three endemic communities of Northeastern Tanzania Acta TROP. 60 (3); 189187. 
Udonsi, JK and Odey, E.O (1985). Filariasis in Yala Areas of Cross River Basin, Nigeria, Nig. $J$. Parasit 6 (1): 4-10.

Udonsi, JK (1986). The status of human filariasis in relation to Clinical signs in endemic areas of the Niger Delta, Ann. Trop. Med. Parasit 90: 424432.

Udonsi, JK (1988). Bancroftian filariasis in the
Igwun Basin, Nigeria.

An

Epidemiological, parasitological and clinical study in relation to the transmission dynamics Acta Trop. 45:171-179.

Weil, CJ; Ramzy, RMR; EL Se'touby, M; Kandil, A M; Ahmed, ES; Faris, R (1999). A longitudinal study of Bancroftian filariasis in the Nile Delata of Egypt: Baseline data and one-year follow-up Am Society of Trop. Med. Hyg 6 (1) 53-88. 